\title{
Analysis on the Current Situation of Grain Minimum Purchase Price Policy in China and Suggestions for Improvement --A Case Study of Wheat in Henan Province
}

\author{
Zhen Chen \\ Shanghai University, Shanghai, China \\ chenzhenjingji@163.com
}

\begin{abstract}
Keywords: Grain minimum procurement price; Grain output; Grain market; Wheat; Policy design
\end{abstract}
\begin{abstract}
Under opening grain purchase and sale policies, China is implementing the minimum purchase price policies. In addition, the policies for grain and paddy should be implemented in 2004 and the wheat be implemented in 2006. During implementing period, the policy exerts to manufacture the prediction. With the help of a series of agricultural policies, it exerts great role in Chinese price steady, market safety, grain market adjustment, protecting the agricultural income, crop seeded area as well as the service macro-adjustment, during the period of minimum purchase price period. However, the policy also faces some shortcoming, including grain procurement subject single, insufficient of acquisition point, grain prices irrational, separation of procurement rights and obligations as well as the policies do not clear and detail the procurement loan and interest subsidy. This paper taking Henan's wheat as the example to analyze the influence of the minimum procurement price from the perspective of farmer income and wheat seeded area as well as proposes the improving suggestions for the implement effects.
\end{abstract}

\section{Introduction}

China's full liberalization of grain purchase and marketing market, the domestic food growers growing enthusiasm, while a series of national support for agricultural policy support, making China's major crop growing areas of the sown area increased and food production surge. In order to avoid the phenomenon of fluctuation of farmland and grain price fluctuation, China introduced and implemented the grain price policy of grain and wheat with the lowest purchase price as the main content in 2004 and 2006 respectively. This policy has played a significant role in regulating the food market price to protect the income of farmers. J. Chen [1] in the wheat after the implementation of the minimum purchase price of one year after the implementation of wheat production in Henan Province and the effect of policy research: they found that the minimum purchase price of wheat basically stabilized the wheat market. However, due to the short duration of policy implementation, lack of policy experience and market data, so the development of the minimum purchase price does not meet the grain market operation mechanism; F.Y. Zou [2] in the study of the minimum purchase price policy proposed to adhere to the grain market circulation reform direction, the establishment of direct subsidies as the core of the minimum purchase price policy, improve the food subsidy policy system; J.P Lan [3] from The quantitative analysis of the results of the implementation of the two aspects of food security and income effect shows that the minimum purchase price has greatly improved the enthusiasm of grain and farmers, food production and farmers' income has increased year by year, while safeguarding the national food security. T. Ge [4] Taking Hubei Province as the research object to analyze the minimum purchase price with the empirical method: the minimum purchase price policy of rice in Hubei Province can guarantee the basic income of farmers and will have positive effect on farmers' agricultural income and rice yield. B.X. Li [5] used the establishment of supply demand equation analysis to achieve the effective implementation of the policy to promote the increase in farmer welfare. However, most of the existing research from the macro level analysis of the minimum purchase price of the policy effect, the minimum purchase price of the crop analysis are also using collective research, resulting in research results are not targeted, lack of practical basis. 
This paper is based on the analysis of the relevant subject of Henan since the implementation of the minimum purchase price of wheat in Henan Province, and discusses the problems found in the policy implementation and gives suggestions for policy improvement.

The minimum purchase price policy of grain is the kind of preferential agricultural policy of the main grain varieties in the market, which is based on the research of the grain market of the major producing areas, and the development of the main grain crops. That is, when the food market price is lower than the state to set the price of the city, the state will start the minimum purchase price policy. By the implementation of the mainstay of the implementation of the policy and its entrusted enterprises in accordance with the price of the acquisition of the city, where private enterprises or unauthorized enterprises or in accordance with the market price of grain purchase; when the market price is higher than or consistent with the country to develop the price of the city, The minimum purchase price policy will not start, the market grain purchase in accordance with the formation of the market mechanism under the effect of the price. For example, in 2004, 2007, 2008 and 2010, rice market in Hubei Province (early indica rice, middle and late indica rice, japonica rice) prices are higher than the price of care, Hubei Province in the year did not start the lowest purchase price, when the rice The purchase price of the market is in accordance with the market price in that year. Wheat prices in Henan Province in 2004 has been declining; in 2005 the price of wheat in Henan fell to the bottom only 0.66 yuan / $\mathrm{kg}$. In 2006, the country implemented the minimum purchase price policy for wheat. Henan Province immediately launched the wheat minimum purchase price policy, so that wheat prices in 2006 rose to a mean of 1.4 yuan $/ \mathrm{kg}$, in the year the market grain purchase price in accordance with the national development of the care City price. The implementation of the minimum purchase price policy has strict rules on the scope of its implementation and grain varieties. The areas covered by China's major grain growing areas include Henan, Anhui, Heilongjiang, Jiangsu, Hunan, Shandong, Sichuan, Hebei, Inner Mongolia, Liaoning, Hubei, Jiangxi and Jilin provinces; food varieties cover wheat (white wheat, red wheat, mixed wheat) and rice (early indica rice, late indica rice, japonica) crops. No minimum purchase price policy can be implemented in other regions or other breeds. The execution price of the minimum purchase price is concentrated during the harvest of the grain. Such as the wheat care city policy implementation time for the end of May to the end of September; early indica rice from mid-July to the end of September; Northeast provinces japonica rice in mid-November to the end of the following year, the remaining provinces and cities in mid-September to the end of December, not During the implementation of the listing price, the acquisition on the grain market is carried out at market prices.

Table 1 and Table 2 are the national implementation of the minimum purchase price list and the minimum purchase price of grain annual growth rate. As can be seen from the table, the state for the lowest purchase price has increased the trend, which wheat in 2009 the lowest purchase price compared with an average increase of $20.47 \%$ last year, the minimum purchase price of wheat an average annual growth rate of $5.03 \%$. However, the minimum purchase price of wheat in the last three years is flat with the previous period, and the minimum purchase price for rice is slightly lowered.

Table 1 Minimum Purchase Price

\begin{tabular}{cccccccccccccc}
\hline & $\mathbf{2 0 0 4}$ & $\mathbf{2 0 0 5}$ & $\mathbf{2 0 0 6}$ & $\mathbf{2 0 0 7}$ & $\mathbf{2 0 0 8}$ & $\mathbf{2 0 0 9}$ & $\mathbf{2 0 1 0}$ & $\mathbf{2 0 1 1}$ & $\mathbf{2 0 1 3}$ & $\mathbf{2 0 1 4}$ & $\mathbf{2 0 1 5}$ & $\mathbf{2 0 1 6}$ & $\mathbf{2 0 1 7}$ \\
\hline $\begin{array}{c}\text { white } \\
\text { wheat }\end{array}$ & & 1.44 & 1.44 & 1.44 & 1.74 & 1.8 & 1.9 & 2.24 & 2.36 & 2.36 & 2.36 & 2.36 \\
\hline $\begin{array}{c}\text { red } \\
\text { wheat }\end{array}$ & & 1.38 & 1.38 & 1.38 & 1.66 & 1.72 & 1.86 & 2.24 & 2.36 & 2.36 & 2.36 & 2.36 \\
\hline $\begin{array}{c}\text { mixed } \\
\text { wheat }\end{array}$ & & 1.38 & 1.38 & 1.38 & 1.66 & 1.72 & 1.86 & 2.24 & 2.36 & 2.36 & 2.36 & 2.36 \\
\hline $\begin{array}{c}\text { early } \\
\text { indica } \\
\text { rice }\end{array}$ & $\underline{1.4}$ & 1.4 & 1.4 & $\underline{1.4}$ & $\underline{1.54}$ & 1.8 & $\underline{1.86}$ & 2.04 & 2.64 & 2.7 & 2.7 & 2.66 & 2.6 \\
\hline $\begin{array}{c}\text { late } \\
\text { indica } \\
\text { rice }\end{array}$ & $\underline{1.44}$ & 1.44 & 1.44 & $\underline{1.44}$ & $\underline{1.58}$ & 1.84 & $\underline{1.94}$ & 2.14 & 2.7 & 2.76 & 2.76 & 2.76 & 2.72 \\
\hline $\begin{array}{c}\text { japonica } \\
\text { rice }\end{array}$ & $\underline{1.5}$ & 1.5 & 1.5 & $\underline{1.5}$ & $\underline{1.64}$ & 1.9 & $\underline{2.1}$ & 2.56 & 3 & 3.1 & 3.1 & 3.1 & 3 \\
\hline
\end{tabular}


Table 2 Grain Minimum Purchase Price Annual Growth Rate (\%)

\begin{tabular}{ccccccccccccc}
\hline & $\mathbf{2 0 0 7}$ & $\mathbf{2 0 0 8}$ & $\mathbf{2 0 0 9}$ & $\mathbf{2 0 1 0}$ & $\mathbf{2 0 1 1}$ & $\mathbf{2 0 1 2}$ & $\mathbf{2 0 1 3}$ & $\mathbf{2 0 1 4}$ & $\mathbf{2 0 1 5}$ & $\mathbf{2 0 1 6}$ & $\mathbf{2 0 1 7}$ & 平均值 \\
\hline $\begin{array}{c}\text { white } \\
\text { wheat }\end{array}$ & 0 & 0 & 20.83 & 3.45 & 5.56 & 7.37 & 9.8 & 5.36 & 0 & 0 & 0 & 4.76 \\
\hline $\begin{array}{c}\text { red } \\
\text { wheat }\end{array}$ & 0 & 0 & 20.29 & 3.61 & 8.14 & 9.68 & 9.8 & 5.36 & 0 & 0 & 0 & 5.17 \\
\hline $\begin{array}{c}\text { mixed } \\
\text { wheat }\end{array}$ & 0 & 0 & 20.29 & 3.61 & 8.14 & 9.68 & 9.8 & 5.36 & 0 & 0 & 0 & 5.17 \\
\hline
\end{tabular}

(Source: National Grain Bureau)

(Note: where the data underlined that the market price of the year higher than the minimum purchase price, the farmers to sell food prices in accordance with market prices, the city did not implement the price)

Crops have the characteristics of long production period, high risk, large fluctuation of grain market price, and grain cultivation is mainly the main source of income for rural residents. Although the state has introduced a series of benefits farmers, agriculture policy, but the food market is the most important is the purchase price, which makes farmers can not predict their earnings, resulting in the embarrassment of crop cultivation. Since the introduction of the minimum purchase price policy and the implementation of this policy to stabilize the food market prices, so that farmers have a positive expectation of the grain market, the equivalent of the farmers to eat a "reassurance." With the minimum purchase price policy as the food market price security, the food market will remain in the vicinity of the market price fluctuations, the amplitude is small, so that not only protect the income of farmers, but also to ensure that the crop sown area.

\section{The Impact of the Minimum Purchase Price Policy of Wheat in Henan Province on the Stakeholders}

Henan Province under the Huanghuai winter wheat area, flat terrain, fertile land, adequate light, moderate rainfall, the natural environment characteristics suitable for wheat growth. Henan Province as one of the 13 grain cultivation and production provinces. As shown in Table 3, wheat production in Henan Province accounted for an average of $26.15 \%$ of the national wheat production, of which wheat production in Henan Province in 2001 accounted for $27.27 \%$ of the national wheat production, wheat sown area accounted for an average of $21.52 \%$ of the wheat sown area. In 2014, wheat acreage in Henan Province accounted for $22.46 \%$ of the total wheat sown area. The data show that Henan Province, regardless of its planting area or wheat production for the country's national grain contribution rate is greater. The effect of the minimum purchase price in the implementation of the Henan province can basically reflect the minimum purchase price policy effect. 
Table 3 Comparison of wheat yield, sown area and national wheat yield and sown area in Henan

\begin{tabular}{|c|c|c|c|c|c|c|}
\hline & \multicolumn{6}{|c|}{ Province } \\
\hline Year & $\begin{array}{l}\text { Wheat } \\
\text { production } \\
\text { (ten } \\
\text { thousand } \\
\text { tons) }\end{array}$ & $\begin{array}{l}\text { National } \\
\text { production }\end{array}$ & proportion & $\begin{array}{l}\text { Wheat } \\
\text { sown area }\end{array}$ & $\begin{array}{l}\text { National } \\
\text { sown area }\end{array}$ & proportion \\
\hline 2000 & 2235.95 & 9963.9 & 22.44 & 4922.3 & 26653 & 18.47 \\
\hline 2001 & 2299.71 & 9387.3 & 24.5 & 4801.6 & 24664 & 19.47 \\
\hline 2002 & 2248.39 & 9029 & 24.9 & 4855.7 & 23908 & 20.31 \\
\hline 2003 & 2292.5 & 8648.8 & 26.51 & 4804.6 & 21997 & 21.84 \\
\hline 2004 & 2480.93 & 9195.2 & 26.98 & 4856 & 21626 & 22.45 \\
\hline 2005 & 2577.69 & 9744.5 & 26.45 & 4962.7 & 22793 & 21.77 \\
\hline 2006 & 2936.5 & 10846.6 & 27.07 & 5208.47 & 23613 & 22.06 \\
\hline 2007 & 2980.21 & 10929.8 & 27.27 & 5213.33 & 23721 & 21.98 \\
\hline 2008 & 3051 & 11246.4 & 27.13 & 5260 & 23617 & 22.27 \\
\hline 2009 & 3056 & 11511.5 & 26.55 & 5263.3 & 24291 & 21.7 \\
\hline 2010 & 3082.22 & 11518.1 & 26.76 & 5280 & 24257 & 21.77 \\
\hline 2011 & 3123 & 11740.1 & 26.6 & 5323.33 & 24270 & 21.93 \\
\hline 2012 & 3177.35 & 12102.4 & 26.25 & 5340 & 24268 & 22 \\
\hline 2013 & 3226.44 & 12192.6 & 26.46 & 5366.66 & 24117 & 22.25 \\
\hline 2014 & 3329 & 12620.8 & 26.38 & 5406.67 & 24069 & 22.46 \\
\hline
\end{tabular}

(Data: China Statistical Yearbook; Henan Statistical Yearbook)

\section{The city's acquisition policy stabilized the grain market.}

The volatility of food prices directly affects farmers' views on the food market. When the food price is stable and the price is reasonable, the growers will actively produce in order to obtain the maximum benefit; when the market price fluctuation is large and the grain price is too low, the farmer's grain is not positive, leading to the decline of grain output, Even worse, will be food security. But the food price is too high, it will affect the consumer's income, making the existing consumers difficult to accept, will affect the economic and social stability. The minimum purchase price in the grain market plays a "stabilizer" role [6].

One of the goals of the minimum purchase price policy is to increase food production. Increasing grain yields from another level of analysis can also indicate an increase in the acreage of the crop. The mechanism of the most purchasing price of wheat can be expressed as follows: the implementation of the minimum purchase price policy can make the farmers have a positive expectation for the food market, farmers will maximize the principle of their income will increase crop acreage. The increase in grain production will also increase in some external effects (the improvement of agricultural machinery technology, etc.), and the increase in grain production will increase the gains in the market in which the minimum purchase price policy is implemented. The mechanism will form a virtuous circle for farmers to promote the stability of the food market, which is consistent with the minimum purchase price policy is expected.

The grain market by the grain storage and its entrusted enterprises to buy, farmers will be in accordance with the price of the market to sell food, often the price of the market than the food market price is higher, so the grain storage and commissioned enterprises will acquire large amounts of food, the state has a sufficient Of the quality of food for the future implementation of grain macro-control has a solid material basis in the face of international turmoil, but also can make the domestic food market is stable.

\section{The city's acquisition policy raised the agricultural income of farmers.}

One of the goals of the minimum purchase price policy is to protect the income of farmers. The minimum purchase price policy gives the farmers a psychological expectation of increasing grain 
income. The price of the city is often higher than that of the grain market. The policy is that the state has the government's lead in coordinating with other beneficiaries and helping farmers to make their farmers fully confident in their policies. At the same time, agricultural production patterns are changing. In the past, grain production, mostly farmers are self-sufficient production mode, but in the grain purchase and marketing market after the full liberalization, farmers are no longer "self-management", farmers will be independent of food production. In the food market, farmers use the "capitalist" to see the food market. The transformation of the production model makes the farmers more consider the interests of the operating, so the minimum purchase price policy, farmers will adjust the supply of food to protect their income level. This is consistent with the expected target for the minimum purchase price policy.

\section{The minimum purchase price increases the cost of the grain processing business.}

Market equilibrium is determined by both parties. When the market reaches equilibrium, the number of suppliers provided by the existing circulation market is equal to the number required by the demand side, and any nonmarket mechanism will cause market distortions. The minimum purchase price policy is the policy of benefiting farmers and helping farmers in order to stabilize grain prices, market safety, grain market regulation and protection of farmers' income, crop acreage. The implementation of the policy is more expensive than the market price, thus distorting the grain market so that the supply and demand of the grain market are no longer equal. At the same time farmers will be in accordance with the price of the city to sell food to the grain and its entrusted enterprises, because it will bring a small risk, high returns. Which makes the country mastered a sufficient quality grain source, the circulation of food on the sharp decline in the market of private enterprises or unauthorized enterprises to reduce the purchase of food, grain processing enterprises need to use the shortage of raw materials for processing.

Henan Province in the implementation of the minimum purchase price policy of wheat, in the new grain into the market, the non-state food processing enterprises can' $t$ on behalf of the storage, and can't be the market price of grain, so that the market will be in the grain storage and commissioned by the enterprise monopoly, So that the market decline in grain flow. At the same time processing enterprises and state-owned grain purchasing and marketing enterprises in the unequal competitive environment, the lack of credit support enterprises, relative to the state-owned grain purchasing and marketing enterprises have loan support and interest subsidies, which makes the processing enterprises to increase the risk of food, Farmers to maximize their interests to consider, but also the sale of grain to the state-owned grain purchasing and marketing enterprises, in a variety of unfavorable conditions, the processing enterprises difficult to buy high-quality wheat in the market, processing enterprises only through the auction to obtain the original grain, Will further improve the price of wheat, making the processing enterprises to further increase the cost. The increase in the cost of processing enterprises will inevitably affect the normal operation of enterprises, making it difficult to bear the high cost of production enterprises have bankruptcy, and Henan Province is not only a large province of wheat production, but also wheat processing and production industry chain province, processing enterprises difficult Operation, is bound to lead to uneven development of the entire market.

\section{The minimum purchase price exists in a series of questions}

During the implementation of the minimum purchase price, the policy meets the expected policy expectations. While maintaining the stability of food prices, food market security and the protection of farmers' income has played an important role in the implementation of the policy also appeared in a series of problems. The emergence of the problem will affect the implementation of the policy effect, even more far from expected expectations. According to the policy implementation process, there are mainly major problems. 


\section{The lowest price of the lowest purchase price, the acquisition of a single subject, power and responsibility asymmetry.}

The minimum purchase price policy to implement the city price is higher than the market price, thus distorting the grain market, so that the grain supply market supply and demand is no longer equal. Such as the grain industry in Henan Province year after year harvest, grain production and marketing gap was narrowed, from the market mechanism, food harvest and supply and demand ease will lead to a decline in food prices. But the state in order to protect the interests of farmers, continuous raise the price level of the city, the price of its care market seriously deviate from the market price; which makes the impact of market mechanisms weakened, distort the market, making the minimum purchase price is not to adjust the market exists in the tool, and Is to make it a grain market, "Paul bottom" price; which makes the non-care market prices during the high market prices, resulting in market price mechanism imbalance, resulting in market regulation price dysfunction.

\section{The relevant policies for the acquisition of loans and interest subsidies need to be further refined and clarified.}

The first is the "library loan separation" problem. In the implementation of the minimum purchase price period, the minimum acquisition of credit to implement the "unified loan system" model, the money lenders are around the Agricultural Bank of the city branch, and the lowest price of grain inventory is the actual supervisor around the county branch, causing funds Loans, grain stocks, respectively, municipal branches and county branches management, an increase of loan risk. The second is the interest transfer problem. The lowest purchase of the bottom of the funds are generally layers of payment path: municipal agricultural development line - in the storage of grain directly under the library - extension of the purchase of the library. The extension of time leads to the issue of interest on in-transit funds [7]. The storage point of the storage is relatively vulnerable to the effective implementation of the policy. At the same time in the allocation process prone to deduct the storage point subsidies, is not conducive to the lowest grain grain storage security and policy implementation.

\section{The lowest purchase price policy single crop variety incomplete, the price difference is unreasonable.}

The minimum purchase price policy is expected to be stable for food prices, market safety, food market regulation and protection of farmers income, crop acreage, service macro-control [8]. But in the development of the minimum purchase price of the implementation of the crop range varieties, no quality crop price of the city. Such as wheat is divided into white wheat, red wheat, mixed wheat three, not the specific development of high quality wheat standards. That is to say, in order to make the crop meet the minimum purchase price requirement of the country, it will plant a large number of crops to meet the requirements, rather than consider planting high quality crops. At the same time the same crop of different varieties of pricing is unreasonable, in the beginning of the implementation of the minimum purchase price of wheat when the wheat and mixed wheat to set the same price, although white wheat than the other two varieties of high prices, but also little difference In 2012 to 2016 the implementation of three varieties of unified pricing principles, making the difference between different varieties. This will lead to farmers will only consider the variety of output, will form a single species of planting, is not conducive to grain structure optimization. A large number of farmers planted "benefits" varieties, making high-quality low-yielding varieties of grain cultivation area is not conducive to the promotion of high-quality grain varieties.

\section{The lowest purchase price of a single sales, sales mechanism is not flexible.}

After the implementation of the minimum purchase price policy, the reduction in the flow of grain in the market, processing enterprises need to collect food from the storage point, but to take the auction transaction. When the market supply of food is relatively tight, the processing enterprises will be herd, 
greatly enhance the price of grain auction, but when the market supply of food is more abundant or smooth, the phenomenon will occur. Which makes the storage point of the enterprise will use this phenomenon artificially create a tight market for food supply. As the storage point has a large number of grain sources and higher than the market price of the purchase price of the price, this "out of the library" phenomenon occurs frequently in the market, which for no reason to increase the cost of processing enterprises, destroying the food market, The formation of dark transactions under the "hidden rules", the impact is very bad.

\section{Policy Suggestion}

\section{Improve the minimum purchase price of grain price system, to rationally pull the quality difference.}

The same variety of different quality of food set the difference. To protect the income of farmers should be short of food varieties as the main acquisition targets. But to form a different variety of food based on the minimum purchase price, and then also to ensure high quality varieties. The quality of low-yield varieties of reasonable premium, for sub-varieties or inferior varieties do not implement the policy of agriculture, so that the grain planting structure can be optimized.

\section{Clear or refine the acquisition of loans and interest subsidies and other related relationships.}

A reasonable solution to the "library loan separation" problem, that is, capital loans, food stocks are managed by the municipal branches or county branches to reduce the risk of loans; to solve the problem of interest transfer. The lowest-priced acquisition does not take the layers of funds, can be set up a special account to the funds directly allocated to the acquisition of the library, so you can avoid the link in the deduction phenomenon. The subsidy for the acquisition and custody shall be calculated from the actual acquisition time. At the same time, the laws and regulations prohibit the process of deducting the subsidy of the storage point.

\section{Establish multi-channel sales mechanism}

In addition to the existing centralized unified auction, online auction auction sales, the state and related departments to open up more sales channels, and strengthen the supervision of the sales process. One: to take a more flexible way and processing transformation and the amount of finished product supply together, give full play to the role of security for the price. Second, it can be producing areas and sales area cooperation. According to the provinces and regions of the sales demand, sales of specialized sales channels. Such as Henan is a large wheat cultivation province, but also wheat processing province, which can be established in Henan Province, "tie" sales mechanism. In the grain storage period, processing enterprises and a storage point enterprises to negotiate a reasonable profit distribution mechanism. But also according to the domestic grain circulation situation, the appropriate adjustment of grain import and export volume, to achieve food supply and demand balance.

\section{The establishment of the acquisition of the main diversification}

The government should encourage private enterprises to participate in the wheat reserve and acquisition market, improve the wheat market system construction, to ensure the formation of wheat purchase price rationality. The diversification of the acquisition subject can also inspire the organizational reform and innovation of the state-owned acquisition enterprise. Making the acquisition of the main competition in a fair environment, to prevent the emergence of state-owned acquisition of the monopoly of the emergence of the market. Cultivate the main body of the market, build large grain enterprise groups, improve the grain logistics system; the development of grain wholesale market, improve its function, so that it truly become an important carrier of national grain 
macro-control. Deepen the grain market circulation reform, improve the efficiency of grain circulation, and actively cultivate diversified market players, and better play the role of the market.

\section{References}

[1] J. Chen, Z.X. Zhang and X. Xu: The World of Survey and Research, Vol.15 (2007) No.11, p.30

[2] F.Y. Zou and N. Guo: Rural Economy, Vol.21 (2009) No.11, p.14

[3] J.P Lan: Research of Agricultural Modernization ,Vol.34 (2013) No.5,

[4] T. Ge: Study on The Effect of Rice Minimum Purchase Price Policy in Hubei Province (MS., Wuhan Polytechnic University, China 2015), p.8

[5] B.X. Li and Y.P. Wang: Journal of Huazhong Agricultural University (Social Sciences Edition), Vol.18 (2016) No.4, p.47

[6] W. He and S.L. Zhu: China Soft Science, Vol.26 (2011) No.09, p.10

[7] J.P Lan: Studies on China Grain minimum purchase price policy (Ph.D., Hunan Agricultural University, China 2013), p.12

[8] Y.H. Guo: Agricultural Development and Finence, Vol.7 (2007) No.5, p.38 